\title{
Mechanics and pavement properties research of nanomaterial modified asphalt
}

\author{
CHEN Shang-jiang ${ }^{1,}$, ZHANG Xiao-ning $^{2, b}$
}

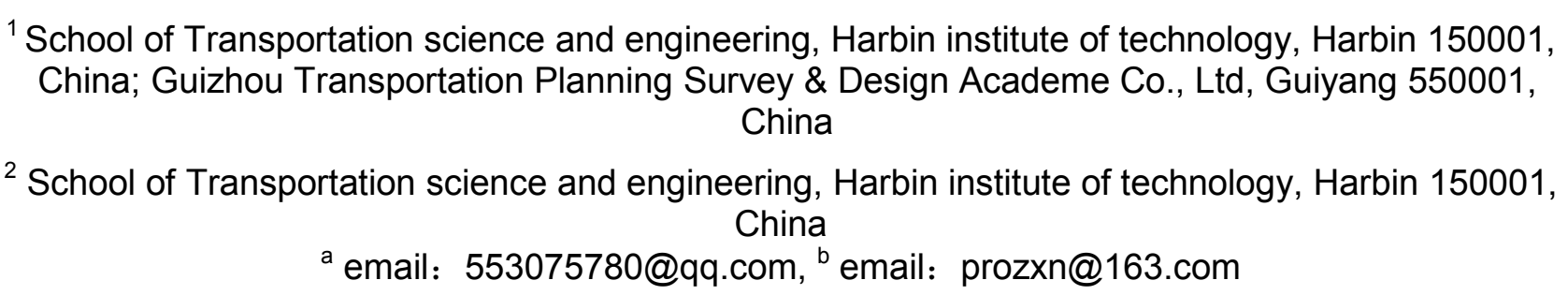

Key Words: Road engineering, nanomaterial modified asphalt, nano powdered rubber, mechanics performance

\begin{abstract}
Nanomaterials (nano powdered rubber VP401, VP501 and sepiolite and $\mathrm{CaCo}_{3}$ composites) were selected to improve the high-temperature and low-temperature performance of asphalt binder. Nanomaterial modified asphalt was prepared using the high shear machine. Laboratory experiments of asphalt binder and asphalt mixture were conducted to evaluate the properties of modified asphalt binder, including the penetration, ductility, softening point, viscosity, and etc. Also, asphalt mixture tests were carried out, such as the cleavage strength test, resilient modulus test, rutting test, water stability test and etc. Based on the test results, asphalt binder modified by $1 \%$ nano powdered rubber VP401 has better performance resistance to low temperature crack and rutting, compared to other nanomaterial modified asphalt binder.
\end{abstract}

\section{Introduction}

Transportation infrastructure construction, especially the highway and rural highway construction, makes communication among the areas more easily, also makes the national travel more convenient. The time required in the trip becomes shorter than before. At the same time, it is good for improving the investment environment, attracting and gathering funds, technology and talents together. These advantages accelerate the regional economic development and regional progress. During the service years, asphalt pavement diseases were come out and emphasized, such as cracking and rutting [1]. In order to delay the asphalt aging time and extend the service life of the asphalt pavement, asphalt modification research is significant from the material standpoint.

Numerous research work of modified asphalt has been done in China. Luan, et al presented the low temperature performance evaluation results of SBS modified asphalt binder [2]. Three kinds of base asphalt binder and five kinds of SBS modified asphalt binder were prepared to be analyzed. Results showed the low temperature performance of SBS modified asphalt was better through the BBR test analysis, and the low temperature property of linear SBS modified asphalt was better than the star SBS modified asphalt. Tan, et al [3] studied the low temperature cracking performance of diatomite asphalt binder and mixture, and analyzed the control asphalt and three kinds of modified asphalt using differential scanning calorimetry (DSC) and temperature-stress analysis. From the results of low temperature bending test, low temperature compression test and shrinkage test, that low temperature of diatomite modified asphalt binder is better than control asphalt binder was concluded. Liu, et al [4] tested the properties of nano calcium carbonate modified asphalt binder and mixture, and test results showed the high temperature performance of $8 \%$ calcium carbonate modified asphalt mixture was improved. In this paper, the three kinds of nanomaterials (VP401, VP501, and composite of nano sepiolite and calcium carbonate) were selected to modify the control asphalt binder. Several dosages of nanomaterials were used by weight in the asphalt modification, and mixing processing was conducted in the high shear machine. The Marshall Binder tests (penetration, softening point, ductility and viscosity) were carried out to evaluate the performance 
of modified asphalt binder. Through the comparison and analysis of test results, the optimum content of nanomaterials was determined. Furthermore, the mechanical and pavement performance tests were used to evaluate the overall properties of nano-modified asphalt mixture. Finally, Test results show the 1\% nano powdered rubber VP401 modified asphalt binder and mixture has better performance compared to the control and other modified asphalt binders and mixtures. Nanomodified asphalt binder also is the hot research direction for asphalt modification in the world. The test work in the paper would show some advices for future research.

\section{Nanomaterials and performance test plan of asphalt mixture}

\section{Modifiers}

Nanomaterials have some special characteristics, such as small size effect, surface effect, and quantum tunneling effect. In the macro physical properties, it can produce the mutation properties of materials, such as making an insulator into a conductor and the conductor into an insulator, magical photoluminescence, photocatalytic sterilization effect, high strength and high toughness. In the past several years, nanotechnology has been gradually applied into pavement material field. Nanomaterials (organic, metal or inorganic non-metallic) were introduced to modify the asphalt binder, and the purpose is to utilize the magic nano-effect to improve the asphalt binder performance. Nano-modified asphalt binder was different from other modified asphalt, because the nanomaterials would have the potential to change the microstructure of modified asphalt binder. However, micro-structure of asphalt determines the macro performance of asphalt binder. So the nanomaterial might fundamentally improve the asphalt performance, also it is a good way to modify the base asphalt. Thus, nano-modified asphalt research would be the hot spot in the research area.

(1) The nano powdered rubber is obtained from irradiating and sulfuring rubber latex particles in dry process. Nano powdered rubber VP401 is a super fine butadiene powdered sulfide rubber, Narpow Nitrile-Butadiene UFPR (ultrafine full-vulcanized powdered rubber), and nano powdered rubber VP501 is a super fine butadiene powdered sulfide rubber, Narpow Carboxylic NitrileButadiene UFPR. Two main functions of the materials are for toughening nylon and modifying the friction materials, such as the polarity plastic and sulfide thermoplastic elastomer materials [5]. The test samples in the study (Narpow nano powdered rubbers) were provided by Beijing chemical institute.

(2) Sepiolite and calcium carbonate: sepiolite clay, gray or grey, low density and the dry powder can float on the surface of water. It has a strong suction, and high absorption rate in the water. It is also like a paste and strong sticky clay. Sepiolite is rich in $\mathrm{Mg}$ fibrous mineral and silicate clay, palygorskites-sepiolite, and has the 2-1 type chains and layers of transitional structure. From the scanning electron microscopy (SEM) images of the sepiolite clay, cross-sectional thickness of sepiolite fiber is only $0.1 \mu \mathrm{m}$, and sepiolite is a kind of ideal nano clay mineral. Calcium carbonate is made from a mechanical method, and directly crushing natural calcite, limestone, and shell using high pressure grinding. Calcium carbonate, a white, odorless and tasteless powder, is almost insoluble in water at the absence of ammonium salt or iron trioxide. Heating results in the decomposition into $\mathrm{CaO}$ and carbon dioxide $(\mathrm{CO} 2)$. It can be a filler for the production of rubber, plastic, paper, paint and ink industry, and widely used in organic synthesis, metallurgy, glass and asbestos and other fields. The test specimen in the study was obtained from Hunan Liuyang sepiolite field [6].

\section{Preparation of nano-modified asphalt binder}

This base asphalt binder (No. 70) was obtained from China national offshore oil corporation. The modified asphalt binder was prepared by the high shear machine at condition of $3000 \mathrm{rpm} / \mathrm{min}$ and around $150^{\circ} \mathrm{C}$. Firstly, nanomaterials $(0.5 \%, 1 \%, 2 \%$, and $3 \%$ nano powdered rubber VP401 and VP501, composites of $1 \%$ sepiolite and $0.5 \%, 1 \%, 2 \%$ calcium carbonate) were slowly added into the base asphalt binder, and mixed in the high shear machine for $60 \mathrm{~min}$. The nano-modified asphalt binder was ready for performance testing. 


\section{Nano-modified asphalt binder and mixture tests}

(1) Basic tests of nano-asphalt binder

Penetration test is often used to determine the asphalt consistency; Softening point test is the basic test of asphalt binder, and it is one of the three indexes which are most commonly used in China. It reflects the asphalt viscosity at high temperatures, directly expresses and relates to the deformation rate; The ductility of asphalt is the sum of deformation when the asphalt binder is stretched; Viscosity are commonly used to determine the mixing and compaction temperatures of asphalt mixture; Penetration, softening point, ductility and viscosity tests were followed by the test procedures (JTJ052-2000) [7].

(2) Mechanical and pavement performance test of nano-asphalt mixture

Cleavage strength test is used to determine the mechanics characteristic of asphalt mixture when the asphalt mixture is at condition of a specified temperature and a loading rate or an elastic fracturing stage. Meanwhile, it would be commonly used for determining the mechanical design parameters in the asphalt pavement structure design and evaluating the low temperature cracking performance of asphalt mixture. Resilience modulus is the mainly material parameters of asphalt mixture. Rutting test is to simulate the wheel loading on pavement and accumulate the deformation of the sample. It is used to evaluate the resistance ability to plastic flow deformation of asphalt mixture at the specific temperature. When the asphalt mixture is soaked in the water, the adhesion between the asphalt and aggregates would be reduced. The water stability of asphalt mixture was expressed by the physical and mechanical properties of asphalt mixture in the water. The residual stability of asphalt mixture in the water after 48 hours is one of evaluation indexes. Cleavage strength, resilience modulus, rutting, water stability tests of asphalt mixture were followed by the asphalt mixture test procedures (JTJ052-2000).

\section{Test results and discussions}

\section{Nano powdered rubber modified asphalt binder}

(1) VP501 modified asphalt binder

First of all, the nano powdered rubber VP501 was slowly added into the control asphalt at the various weight percentages. Then, the modified asphalt was mixed in the high shear machine and the nano-modified asphalt was formed. The performance tests of asphalt binder were conducted and the test results are shown in Table 1.

Table 1 Tests results of VP501 modified asphalt

\begin{tabular}{cccccc}
\hline Properties & \multicolumn{5}{c}{ Concentrations of VP501 } \\
& Base asphalt & $\mathbf{0 . 5 \%}$ & $\mathbf{1 \%}$ & $\mathbf{2 \%}$ & $\mathbf{3 \%}$ \\
\hline Softening point $\left({ }^{\circ} \mathrm{C}\right)$ & 48.3 & 51.8 & 52.0 & 52.3 & 52.5 \\
Penetration $(\mathrm{dmm})$ at $5^{\circ} \mathrm{C}$ & 12 & 11 & 11 & 10 & 9 \\
Penetration $(\mathrm{dmm})$ at $15^{\circ} \mathrm{C}$ & 28 & 25 & 23 & 24 & 23 \\
Penetration $(\mathrm{dmm})$ at $25^{\circ} \mathrm{C}$ & 68 & 64 & 61 & 58 & 53 \\
Penetration index $(\mathrm{PI})$ & 0.405 & 0.302 & 0.490 & 0.314 & 0.256 \\
Equivalent softening point $\mathrm{T}_{800}\left({ }^{\circ} \mathrm{C}\right)$ & 53.500 & 53.911 & 55.513 & 54.870 & 55.423 \\
Equivalent breaking point $\mathrm{T}_{1.2}\left({ }^{\circ} \mathrm{C}\right)$ & -21.472 & -19.938 & -20.405 & -19.110 & -17.922 \\
Ductility $(\mathrm{cm})$ at $5^{\circ} \mathrm{C}, 5 \mathrm{~cm} / \mathrm{min}$ & 5 & 9 & 9 & 9 & 7 \\
Ductility $(\mathrm{cm})$ at $25^{\circ} \mathrm{C}, 5 \mathrm{~cm} / \mathrm{min}$ & $>100$ & $>100$ & $>100$ & $>100$ & 85 \\
Viscosity $(\mathrm{Pa} \cdot \mathrm{s})$ at $135^{\circ} \mathrm{C}$ & 1.312 & 1.582 & 1.408 & 1.528 & 2.112 \\
\hline
\end{tabular}

From Table 1, test results show the effect of nano powdered rubber VP501 on the performance improvement of modified asphalt binder. The softening point of modified asphalt was significantly improved compared to the base asphalt, even reach to $52.5^{\circ} \mathrm{C}$, and the softening point increased by increasing the concentration of nano powered rubber VP501. About the penetration and ductility of modified asphalt at $15^{\circ} \mathrm{C}$, they decreased with the content increase of VP501. Penetration index, equivalent softening point and equivalent breaking point of modified asphalt binder presented the 
same trend. They showed that the overall property of $1 \%$ nano powered rubber VP501 was improved most, and the high temperature performance of 1\% VP501 modified asphalt was significantly enhanced. However, the low temperature performance of modified asphalt might decrease. Therefore, 1\% VP501 is the best content for the asphalt modification.

(2) VP401 modified asphalt binder

Similarly, the same dosages of nano powdered rubber VP401 were added into the base asphalt and the modified asphalt was mixed in the high shear machine. The test results are shown in Figure 2.

Table 2 Tests results of VP401 modified asphalt

\begin{tabular}{cccccc}
\hline Properties & \multicolumn{5}{c}{ Concentrations of VP401 } \\
Softening point $\left({ }^{\circ} \mathrm{C}\right)$ & Base asphalt & $\mathbf{0 . 5 \%}$ & $\mathbf{1 \%}$ & $\mathbf{2 \%}$ & $\mathbf{3 \%}$ \\
\hline Penetration $(\mathrm{dmm})$ at $5^{\circ} \mathrm{C}$ & 48.3 & 54.9 & 54.3 & 54.8 & 55.8 \\
Penetration $(\mathrm{dmm})$ at $15^{\circ} \mathrm{C}$ & 12 & 9 & 9 & 8 & 7 \\
Penetration $(\mathrm{dmm})$ at $25^{\circ} \mathrm{C}$ & 28 & 20 & 21 & 21 & 22 \\
Penetration index $(\mathrm{PI})$ & 68 & 53 & 52 & 50 & 44 \\
Equivalent softening point $\mathrm{T}_{800}\left({ }^{\circ} \mathrm{C}\right)$ & 53.500 & 55.948 & 56.280 & 55.081 & 55.736 \\
Equivalent breaking point $\mathrm{T}_{1.2}\left({ }^{\circ} \mathrm{C}\right)$ & -21.472 & -17.397 & -17.862 & -15.882 & -15.607 \\
Ductility $(\mathrm{cm})$ at $5{ }^{\circ} \mathrm{C}, 5 \mathrm{~cm} / \mathrm{min}$ & 5 & 8 & 8 & 8 & 7 \\
Ductility $(\mathrm{cm})$ at $25^{\circ} \mathrm{C}, 5 \mathrm{~cm} / \mathrm{min}$ & $>100$ & $>100$ & $>100$ & 92 & 64 \\
\hline
\end{tabular}

From Table 2, the test results exhibit the influence of nano powdered rubber VP401 on the performance improving of modified asphalt. The softening point of VP401 modified asphalt increased as increasing the VP401 content, and compared to the base asphalt, it was greatly improved. Ductility of VP401 modified asphalt at the temperatures of $15^{\circ} \mathrm{C}$ and $5^{\circ} \mathrm{C}$ decreased and the low temperature performance of modified asphalt might reduce. Penetration index, equivalent softening point and equivalent breaking point of VP401 modified asphalt had the similar trend, which showed that the temperature susceptibility of modified asphalt reduced, and 1\% VP401 modified asphalt has the best overall performance. Thus, the high temperature performance of VP401 modified asphalt was greatly improved, and 1\% nano powered rubber VP401 was the best concentration for the asphalt modification.

(3) Sepiolite and $\mathrm{CaCO}_{3}$ modified asphalt binder

Sepiolite and calcium carbonate at certain weigh percentages were added into the base asphalt. The modified asphalt was mixed in the high shear machine and the binder tests were conducted. The experimental results are shown in Table 3.

Table 3 Tests results of Sepiolite and $\mathrm{CaCO}_{3}$ modified asphalt

\begin{tabular}{|c|c|c|c|c|}
\hline \multirow{2}{*}{ Properties } & \multicolumn{4}{|c|}{ Concentrations of Sepiolite and $\mathrm{CaCO}_{3}$} \\
\hline & Base asphalt & $1 \% \mathrm{~S}+0.5 \% \mathrm{C}$ & $1 \% \mathrm{~S}+1 \% \mathrm{C}$ & $1 \% \mathrm{~S}+2 \% \mathrm{C}$ \\
\hline Softening point $\left({ }^{\circ} \mathrm{C}\right)$ & 48.3 & 48.0 & 46.8 & 46.2 \\
\hline Penetration $(\mathrm{dmm})$ at $5^{\circ} \mathrm{C}$ & 12 & 11 & 10 & 9 \\
\hline Penetration $(\mathrm{dmm})$ at $15^{\circ} \mathrm{C}$ & 28 & 24 & 23 & 21 \\
\hline Penetration $(\mathrm{dmm})$ at $25^{\circ} \mathrm{C}$ & 68 & 65 & 63 & 62 \\
\hline Penetration index (PI) & 0.405 & 0.243 & 0.005 & -0.308 \\
\hline Equivalent softening point $\mathrm{T}_{800}\left({ }^{\circ} \mathrm{C}\right)$ & 53.500 & 53.666 & 52.933 & 51.910 \\
\hline Equivalent breaking point $\mathrm{T}_{1.2}\left({ }^{\circ} \mathrm{C}\right)$ & -21.472 & -19.538 & -17.723 & -15.474 \\
\hline Ductility $(\mathrm{cm})$ at $5^{\circ} \mathrm{C}, 5 \mathrm{~cm} / \mathrm{min}$ & 5 & 8 & 8 & 8 \\
\hline Ductility $(\mathrm{cm})$ at $25^{\circ} \mathrm{C}, 5 \mathrm{~cm} / \mathrm{min}$ & $>100$ & $>100$ & $>100$ & $>100$ \\
\hline
\end{tabular}

From Table 3, the test results showed that the overall performance of modified asphalt decreased compared to the base asphalt when the Sepiolite and calcium carbonate were added into the base asphalt. The low temperature performance of modified asphalt was significantly decreased, 
and high temperature of modified asphalt might slightly increase. Penetration index, equivalent softening point, equivalent breaking point had a peak point at $1 \%$ sepiolite $+0.5 \%$ calcium carbonate modified asphalt. Thus, $1 \%$ sepiolite $+0.5 \%$ calcium carbonate relatively might be the best content for the asphalt modification from test results.

\section{Mechanical and pavement test of modified asphalt mixture}

Asphalt mixture has been widely used for the pavement construction, and asphalt mixture should be able to withstand the large traffic loading and natural environment changing. The strength of asphalt mixture directly influences the performance and service life of pavement, also relates to the pavement maintenance cost. At the low temperature the temperature shrinkage stress exceeds the range of asphalt mixture, and the pavement cracking would occur. At the high temperature, the shear stress of pavement would be out of range, the rutting would appear. The Strength of asphalt mixture is mainly determined by the bonding among aggregates and adhesion between asphalt and aggregates. Asphalt performance, aggregate gradation and characteristics are the key factors of asphalt pavement. The gradation of asphalt mixture in this study is AC-13. Cleavage strength of asphalt mixture was tested by the material testing machine at the condition of $15^{\circ} \mathrm{C}, 50 \mathrm{~mm} / \mathrm{min}$ loading rate and 0.30 Poisson ratio. Resilient modulus of asphalt mixture was tested by the universal testing machine at the condition of 0.35 poisson ratio and $20^{\circ} \mathrm{C}$. The automatic rutting test instrument was used for the rutting test. The testing temperature is $60^{\circ} \mathrm{C} \pm 0.5^{\circ} \mathrm{C}$, and the sample dimension is $30 \mathrm{~cm} \times 30 \mathrm{~cm} \times 5 \mathrm{~cm}$. The water stability of asphalt mixture was measured by the Marshall residual stability, and test specimen was formed by the Marshall testing instrument. Test results of cleavage strength; resilient modulus, rutting, and water stability are shown from Figure 1 to Figure 3.

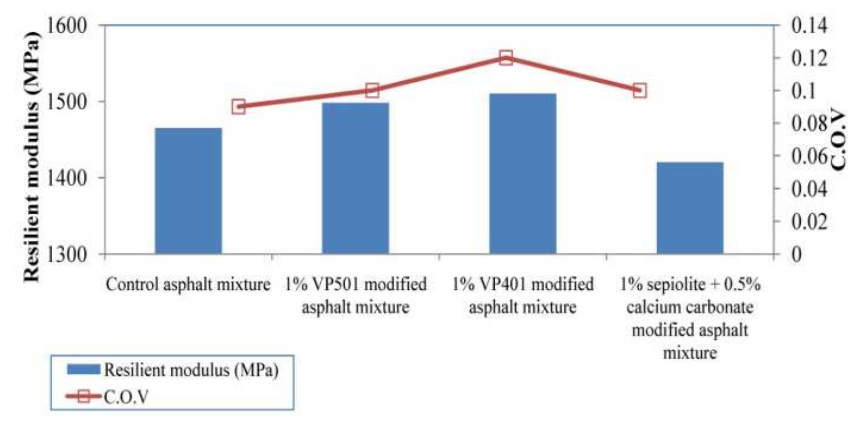

(a) Resilient modulus results

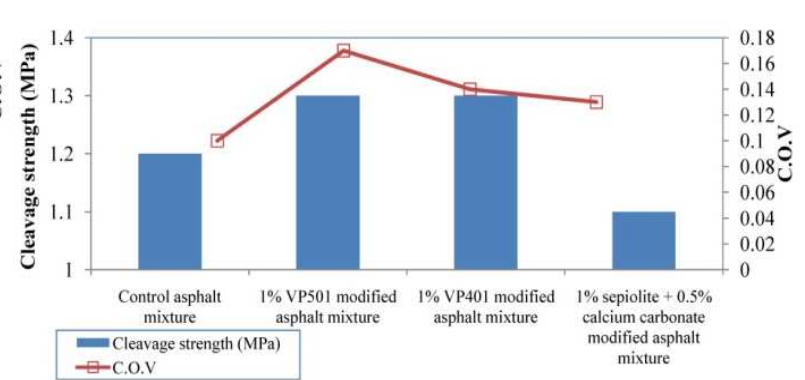

(b) Cleavage strength results

Figure 1. Resilient modulus and cleavage strength and results of asphalt mixtures

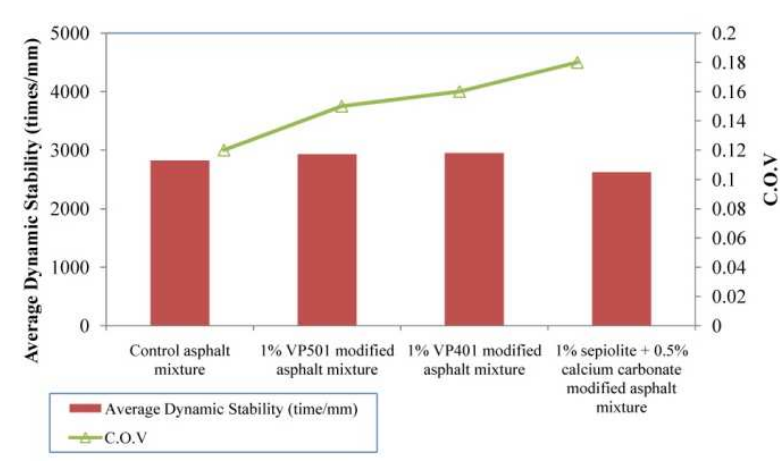

Figure 2. Rutting tests results of nano-materials modified asphalt mixtures

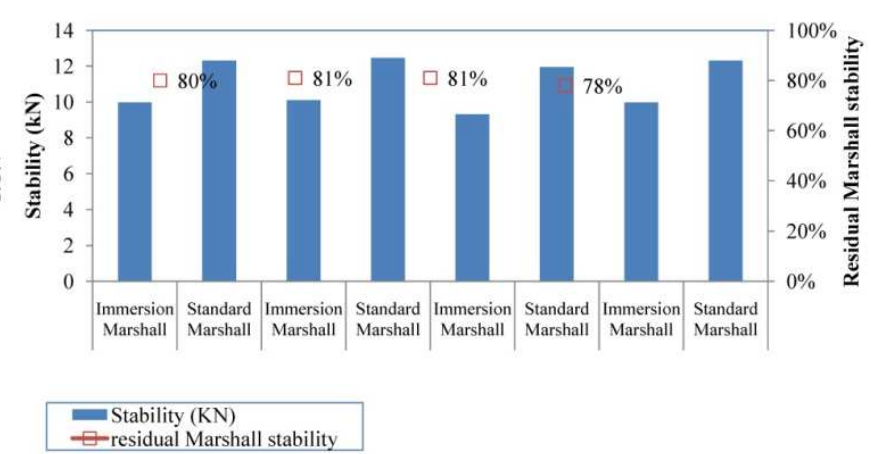

Figure 3. Water stability results of nano-materials modified asphalt mixtures 


\section{Conclusions}

Based on the test results, the following conclusions can be drawn.

(1) The basic properties of nano-modified asphalt binders show that when the nano powdered rubbers VP401 and VP501, 1\% sepiolite $+0.5 \%$ calcium carbonate were added into the base asphalt, the softening point and equivalent softening point were improved. Therefore, these kinds of nanomodified asphalt can improve the overall performance of asphalt pavement most, especially in the high temperature property.

(2) The test results show the 1\% nano powered rubber VP401 and VP501 modified asphalt have high cleavage strength, high resilience modulus, good high temperature performance, good water stability compared to other asphalt mixtures. Therefore, nano powered rubber VP401 and VP501 would be the best modifier in this study.

In summary, from the test results, the 1\% nano powered rubber VP401 and VP501 modified asphalt binder and mixture would have good performance to resist permanent deformation and prevent fatigue cracking.

\section{References}

[1] F. Ma. Research on performance of pavement and modification mechanism of Nano-CaCO3 modified asphalt. Xi'an: Chang' an University, 2004.

[2] Z. S. Luan, J. Q. Lei, Q.U. Pu and H. X. Chen. Evaluation methods of SBS Modified asphalt binders. Journal of Wuhan University of Technology, 2010, 32(2):15-18.

[3] TAN Yi-qiu, SHAN Li-yan, FANG Jun and ZHANG Xing-you. Anti-cracking mechanism of diatomite asphalt and diatomite asphalt mixture at low temperature. Journal of Southeast University (English Edition), 2009, 25(1):74-78.

[4] D. L. Liu, A. J. Yue and L. Chen. A study of the performance of Nano Calcium Carbonate modified asphalt and the mixture. Journal of Changsha Communications University, 2004, 20(4): 70-72.

[5] Y. Q. Liu, Z. Q. Fan, H.Y. Ma, Y. Tan and J. L. Qiao. Application of nano powdered rubber in friction materials. Wear, 2006, 261(2):225-229.

[6] E. Sabah, M. Majdan. Removal of phosphorous from vegetable oil by acid-activated sepiolite. Journal of Food Engineering, 2009, 91(3):423-427.

[7] L. Xiang, J. Cheng and G. H. Que. Microstructure and performance of crumb rubber modified asphalt. Construction and Building Materials, 2009, 23(12):3586-3590. 